\title{
EFFECT OF ACETATE SUBSTITUENTS ON THE CONFORMATIONS OF DI- AND POLYSACCHARIDES
}

\author{
R. H. Marchessault and P. R. Sundararajan \\ Department of Chemistry, Université de Montréal, \\ Montréal, Québec, Canada
}

\begin{abstract}
In an effort to analyse the conformational differences which arise due to acetyl substituents in polysaccharides, crystal structure data on free and acetylated disaccharides are compared. Marked differences are found in the torsional angles around the skeletal bonds as well as the glycosidic bonds in cellobiose compared with acetyl cellobiose. The cause and the significance of such variations are examined in terms of calculated conformational energy maps. Calculations suggest the possibility of extrapolating the results on disaccharides to predict the structural differences in the respective free and acetylated polysaccharide counterparts. It is concluded that any theoretical investigation on free or acetylated polysaccharide should be conducted only with data derived from the identically related oligomeric crystal structures. When this is done for acetyl xylan and acetyl mannan, one can readily explain why the former changes from threefold to twofold chain symmetry and vice versa for the latter when one goes from the native polysaccharide to the acetate derivative. Comparison of cellobiose and acetyl cellobiose conformational energy maps shows that in the former intramolecular hydrogen bonds are much more important conformational influences than intermolecular ones, while in the latter non-bonded steric effects are the dominant factor.
\end{abstract}

\section{INTRODUCTION}

Many of the naturally occurring polysaccharides are often found to be partially acetylated ${ }^{1,2}$. Analysis of crystalline conformations by $\mathrm{x}$-ray diffraction methods has shown that the chain symmetry of free and acetyl derivatives of polysaccharides differs significantly ${ }^{3-10}$. Examples of this are listed in Table 1. It seems likely that the observed changes in the fibre repeat and the screw symmetry of the helical polymer chain are the result of steric imperatives. Such spatial adjustments could be due either to intramolecular or intermolecular interactions, or both. The importance of understanding the role played by the substituents in their influence on the preferred conformation of the polymer cannot be overemphasized, since the local conformation of a polysaccharide greatly influences its chemical and physical properties, and appears to be a determining factor in enzymatic recognition ${ }^{11}$.

Evidence has accumulated in recent years that the short-range preferred conformation of a polymer is close to that of the related dimer or oligomer. Differences in the conformational features of free and acetyl derivatives of 
R. H. MARCHESSAULT AND P. R. SUNDARARAJAN

Table 1. A comparison of the chain conformation of acetyl and free polysaccharides

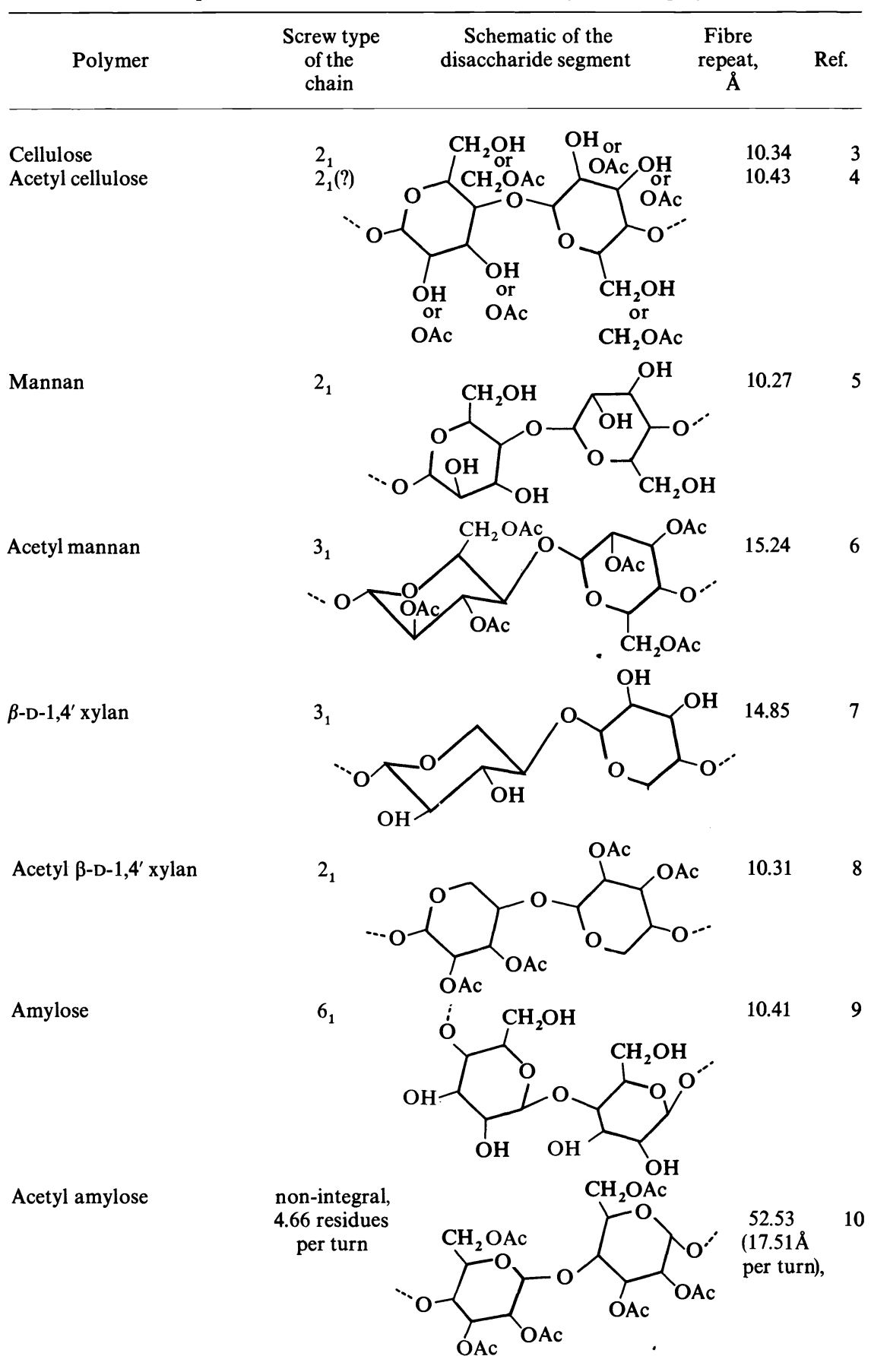


disaccharides immediately suggest that the related free and acetylated polysaccharides will show the same conformational differences. Since there is a paucity of crystal data on oligomeric structures related to natural polysaccharides, one often wishes to use crystal conformation data on peracetylated or free oligomers as if they were the same. The purpose of this study is to show that this approach is fraught with danger because acetyl substitution has a significant effect on the torsional angles of acetyl oligomers compared with the free sugar oligomer. Furthermore these differences are responsible for the above-mentioned variations in crystalline chain symmetry as one goes from the free to the acetylated polysaccharide (Table 1).

\section{CRYSTALLINE CONFORMATIONS OF DISACCHARIDES}

The crystalline conformations of disaccharides related to naturally occurring polysaccharides which have been so far reported include: maltose ${ }^{12,13}$, cellobiose ${ }^{14}$, acetyl cellobiose ${ }^{15}$ and acetyl xylobiose ${ }^{16}$. Neither free xylobiose nor mannobiose structures have been reported to date, nor the acetyl derivatives of maltose and mannobiose. From the crystal structure data one may readily derive the torsion or dihedral angles in the ring structures and thereby compare the ring shapes of free and acetyl sugars in disaccharides.

The relative orientation of contiguous rings is dictated by the torsional angles around the glycosidic bonds. These also are derivable from the disaccharide crystal data and relate most readily to polysaccharide conformational information.

\section{Torsional angles in the rings}

Schematic diagrams of cellobiose and acetyl cellobiose are given in Figure 1 along with the atom numbering and the torsional angles relevant for the discussion.

The torsion angles (conformation angles) about the various skeletal bonds of the pyranose ring are given in projection in Figure 2. The numerical values are listed below each projection. The sign of the angles is given in adherence to the IUPAC nomenclature ${ }^{17}$. The projections are so drawn as to always render the angles marked $A$ positive and those marked $B$ negative. The torsion angles in the crystal structures of 'hexapyranose-containing' sugars, viz. $\beta$-D-glucose ${ }^{14}$, cellobiose ${ }^{14}$, acetyl cellobiose ${ }^{15}$, are listed along with the 'standard' $\beta$-D-glucose residue proposed by Arnott and Scott ${ }^{18}$. Also given in Figure 2 are the angles in the 'pentapyranose-containing' sugars: $\beta$-D-xylose ${ }^{19}$ and acetyl xylobiose ${ }^{16}$.

Examination of Figure 2 shows that the torsion angles involving ring atoms, e.g. $[O(5)-C(1)-C(2)-C(3)],[C(2)-C(3)-C(4)-C(5)]$, etc., are generally comparable to those of the standard residue. However, among the hexapyranose disaccharides, the torsion angles involving the extracyclic oxygen atoms show large variations: e.g. $[\mathrm{O}(1)-\mathrm{C}(1)-\mathrm{C}(2)-\mathrm{O}(2)]=-55^{\circ},\left[\mathrm{O}\left(1^{\prime}\right)-\mathrm{C}\left(1^{\prime}\right)-\mathrm{C}\left(2^{\prime}\right)-\right.$ $\left.O\left(2^{\prime}\right)\right]=-67.6^{\circ}$ in cellobiose, while the same angles are respectively $-64.7^{\circ}$ and $-73.8^{\circ}$ in acetyl cellobiose; $[\mathrm{O}(2)-\mathrm{C}(2)-\mathrm{C}(3)-\mathrm{O}(3)]=55.9^{\circ}$, $\left[\mathrm{O}\left(2^{\prime}\right)-\mathrm{C}\left(2^{\prime}\right)-\mathrm{C}\left(3^{\prime}\right)-\mathrm{O}\left(3^{\prime}\right)\right]=65.8^{\circ}$ in cellobiose compared with $74.6^{\circ}$ and $76.6^{\circ}$ in acetyl cellobiose. The trend is such that the value of the torsional angle between equivalent extracyclic oxygen atoms is consistently greater in 


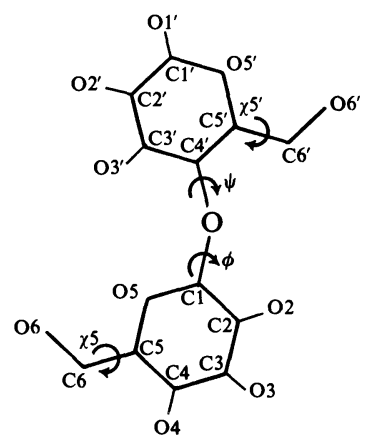

(a)

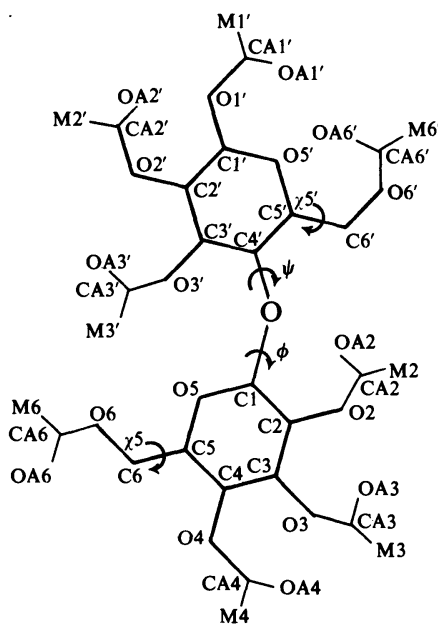

(b)

Figure 1. Schematic diagram of (a) cellobiose and (b) acetyl cellobiose. The angles $\chi$ relevant for discussion are also shown. Note that the atom names in the reducing residue are primed. The side group conformations as shown here are arbitrary

acetyl cellobiose than in cellobiose or the standard $\beta$-D-glucose residue. It must be remembered that Figure 2 compares two types of structures, one of which is stabilized by inter- and intramolecular hydrogen bonds $(a, b, e)$ and the other, by predominantly van der Waals forces (c, f); the 'standard residue' (d) was derived from average bond lengths, bond angles and torsion angles for various carbohydrate crystal structures which differ considerably in the pattern of inter- and intramolecular forces. The objective here is to impress that significant differences in torsional angles follow as one proceeds to replace the hydroxyls with $O$-acetyl groups in hexapyranose sugars. However,

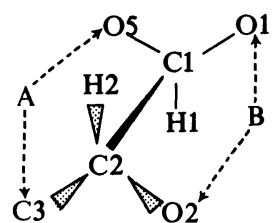

A

$\left.\begin{array}{lcl} & \text { A } & \multicolumn{1}{c}{\text { B }} \\ \text { (a) } & 53.7 & -69.2 \\ \text { (b) } & 63.5 & -55.0 \\ \text { (b') } & 57.8 & -67.6 \\ \text { (c) } & 59.3 & -64.7 \\ \text { (c) } & 56.6 & -73.8 \\ \text { (d) } & 57.5 & -63.6 \\ \text { (e) } & 60.3 & -63.4 \\ \text { (f) } & 60.3 & -64.2 \\ \text { (f) } & 57.6 & -65.3\end{array}\right\}$

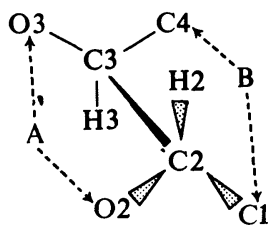

A $\quad$ B

$68.9-50.8$

$\begin{array}{rr}55.9 & -57.3 \\ 65.8 & -50.7\end{array}$

$\left.\begin{array}{rr}65.8 & -50.7\end{array}\right\}$

$\begin{array}{ll}74.6 & -50.0\end{array}$

$\left.\begin{array}{rr}76.6 & -45.0\end{array}\right\}$

$64.6-53.2$

$64.6-51.9$

$68.8-55.1\}$

$\left.\begin{array}{ll}72.2 & -48.4\end{array}\right\}$

402

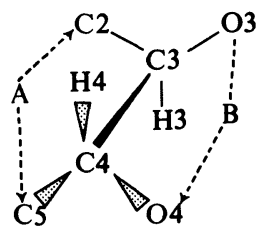

$\left.\begin{array}{cc}\text { A } & \multicolumn{1}{c}{\text { B }} \\ 53.4 & -67.5 \\ 52.0 & -63.5 \\ 48.0 & -73.7 \\ 49.2 & -80.5 \\ 43.8 & -75.6 \\ 52.2 & -67.0 \\ 48.8 & -70.0 \\ 54.1 & -65.1 \\ 48.0 & -73.6\end{array}\right\}$




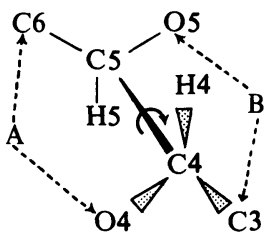

$\left.\begin{array}{lcc} & \text { A } & \text { B } \\ \text { (a) } & 59.6 & -59.8 \\ \text { (b) } & 72.3 & -51.9 \\ \text { (b') } & 71.1 & -51.1 \\ \text { (c) } & 66.1 & -56.8 \\ \text { (c') } & 71.7 & -56.0 \\ \text { (d) } & 63.7 & -56.0 \\ \text { (e) } & - & -53.0 \\ \text { (f) } & - & -57.5 \\ \text { (f') } & - & -54.3\end{array}\right\}$

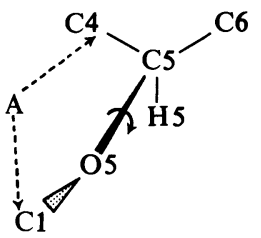

A

66.3

$59.8\}$

$60.9\}$

67.7 \}

$68.4\}$

62.4

63.0

62.7 ,

$62.9\}$<smiles>O[AlH]1C[Te]O[GeH]1</smiles>

$$
\begin{aligned}
& \text { B } \\
& -62.8 \\
& -65.7 \\
& -65.1\} \\
& -70.1\} \\
& -69.8 \text {, } \\
& -62.7 \\
& -67.4 \\
& -63.8\} \\
& -65.6\}
\end{aligned}
$$

Figure 2. Schematic diagram showing the torsion angles around the skeletal bonds of the pyranose ring. The signs of the angles conform to IUPAC nomenclature ${ }^{17}$. The numerical values correspond as follows: (a) $\beta$-D-glucose ${ }^{14}$; (b, $\left.\mathrm{b}^{\prime}\right)$ unprimed and primed residues in cellobiose ${ }^{14}$; $\left(c, c^{\prime}\right)$ unprimed and primed residues in acetyl cellobiose ${ }^{15}$; (d) standard $\beta$-D-glucose unit ${ }^{18}$; (e) $\beta$-D-xylose ${ }^{19} ;$ and $\left(f, f^{\prime}\right)$ unprimed and primed residues in acetyl xylobiose $e^{16}$

the pentapyranose sugars $\beta$-D-xylose and acetyl xylobiose show very little difference in their torsion angles.

\section{Torsional angles about the glycosidic bonds}

The projections given in Figure 3 describe the torsion angles around the glycosidic bonds, $\mathrm{C}(1)-\mathrm{O}$ and $\mathrm{O}-\mathrm{C}\left(4^{\prime}\right)$. The angles $\mathrm{H}(1)-\mathrm{C}(1)-\mathrm{O}-\mathrm{C}\left(4^{\prime}\right)$ and $\mathrm{C}(1)-\mathrm{O}-\mathrm{C}\left(4^{\prime}\right)-\mathrm{H}\left(4^{\prime}\right)$ are customarily denoted as the conformation angles

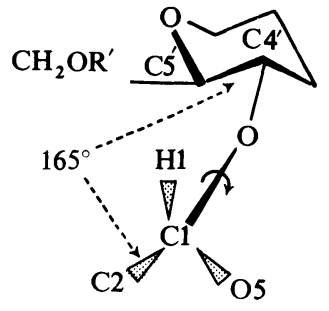

(a)

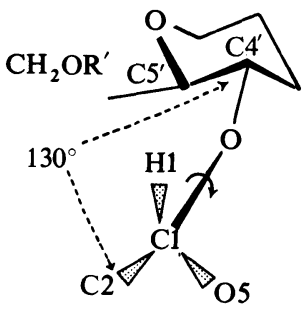

(b)

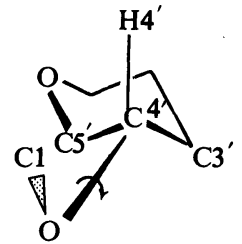

(c)

$$
\begin{gathered}
\text { Torsion Angle } \\
\Phi \rightarrow \mathrm{H}(1)-\mathrm{C}(1)-\mathrm{O}-\mathrm{C}\left(4^{\prime}\right) \\
\mathrm{C}(2)-\mathrm{C}(1)-\mathrm{O}-\mathrm{C}\left(4^{\prime}\right) \\
\mathrm{O}(5)-\mathrm{C}(1)-\mathrm{O}-\mathrm{C}\left(4^{\prime}\right) \\
\psi \rightarrow \mathrm{C}(1)-\mathrm{O}-\mathrm{C}\left(4^{\prime}\right)-\mathrm{H}\left(4^{\prime}\right) \\
\mathrm{C}(1)-\mathrm{O}-\mathrm{C}\left(4^{\prime}\right)-\mathrm{C}\left(5^{\prime}\right) \\
\mathrm{C}(1)-\mathrm{O}-\mathrm{C}\left(4^{\prime}\right)-\mathrm{C}\left(3^{\prime}\right)
\end{gathered}
$$

$$
\begin{gathered}
\text { Acetyl } \\
\text { Cellobiose } \\
44.1^{\circ} \\
165.2^{\circ} \\
-77.1^{\circ} \\
15.7^{\circ} \\
-103.8^{\circ} \\
133.5^{\circ}
\end{gathered}
$$

$$
\begin{array}{r}
\text { Acetyl } \\
\text { Xylobiose } \\
15.8^{\circ} \\
137.0^{\circ} \\
-104.7^{\circ} \\
-31.9^{\circ} \\
-149.2^{\circ} \\
89.5^{\circ}
\end{array}
$$

Figure 3. Schematic diagram showing the torsion angles around the $\mathrm{C}(1)-\mathrm{O}$ and $\mathrm{O}-\mathrm{C}\left(4^{\prime}\right)$ bonds in the crystal structures of cellobiose, acetyl cellobiose and acetyl xylobiose 
$\phi$ and $\psi$; these establish the relative orientation of contiguous residues*. Comparing the entries in Figure 3 we find that there is very little difference in the torsion angles about the $\mathrm{C}(1)-\mathrm{O}$ bond between cellobiose and acetyl cellobiose. In acetyl xylobiose the value of $\phi$ is close to the cis conformation. The bond $\mathrm{O}-\mathrm{C}\left(4^{\prime}\right)$ is close to $\pm 120^{\circ}$ with respect to the bonds $\mathrm{C}(1)-\mathrm{C}(2)$ and $\mathrm{C}(1)-\mathrm{O}(5)$. Both in cellobiose and in acetyl cellobiose, which carry substituents on $\mathrm{C}(5)$ and $C\left(5^{\prime}\right)$ atoms, the angle $\mathrm{C}(2)-\mathrm{C}(1)-\mathrm{O}-\mathrm{C}\left(4^{\prime}\right)$ is close to $180^{\circ}$ [Figure 3(a)], thereby relieving the steric overlap that would occur otherwise [Figure $3(b)$ ] between the $\left(\mathrm{CH}_{2} \mathrm{OR}\right)$ group in the primed residue and the group attached to the $\mathrm{C}(2)$ atom. The conformation in which the bond $\mathrm{O}-\mathrm{C}\left(4^{\prime}\right)$ is trans to the $\mathrm{C}(1)-\mathrm{O}(5)$ bond, is not found in any of the three disaccharides: examination of scale models would show that in such a situation close contacts exist between atoms of the contiguous residues, irrespective of the rotation of the primed residue about the $\mathrm{O}-\mathrm{C}\left(4^{\prime}\right)$ bond.

The angle $\psi$, around the $\mathrm{O}-\mathrm{C}\left(4^{\prime}\right)$ bond, shows wide variations. It is most negative for acetyl xylobiose and positive for acetyl cellobiose. Intramolecular interactions between contiguous residues seem to be the reason for such differences, as we shall discuss later. The angle around the $\mathrm{O}-\mathrm{C}\left(4^{\prime}\right)$ bond is such that the bond $\mathrm{C}(1)-\mathrm{O}$ is about $\pm 120^{\circ}$ with respect to $\mathrm{C}\left(3^{\prime}\right)$ or $\mathrm{C}\left(5^{\prime}\right)$ in cellobiose and acetyl cellobiose, while it is close to trans with respect to $\mathrm{C}\left(5^{\prime}\right)$ in acetyl xylobiose.

\section{Conformation of $\left(\mathrm{CH}_{2} \mathrm{OR}\right)$ group}

Figure 4 shows the conformation of the $\mathrm{O}(6)$ group $\left[\chi(5)=60^{\circ}\right.$ or $\left.-60^{\circ}\right]$ about the $\mathrm{C}(5)-\mathrm{C}(6)$ bond in various mono- and disaccharide crystal
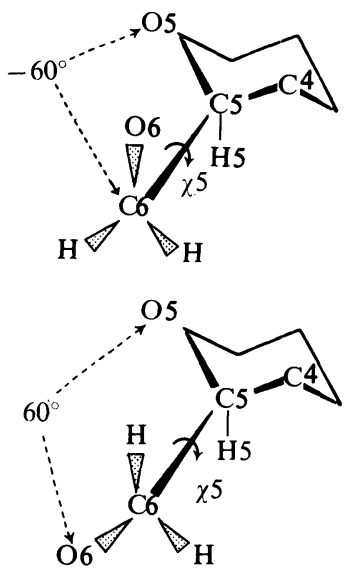

$\beta$-D-glucose $e^{14}$; acetyl cellobiose unprimed residue $e^{15}$ maltose primed residue $e^{12}$

Cellobiose ${ }^{14}$, both residues; acetyl cellobiose ${ }^{15}$ primed residue; maltose ${ }^{12}$, unprimed residue; $\alpha-\mathrm{D}-$ glucose $^{20}$

Figure 4. Schematic showing the approximate orientation of $\mathrm{C}(6)-\mathrm{O}(6)$ bond in various monoand disaccharide crystal structures involving glucose. Note that this torsion angle $[\mathrm{O}(5)-\mathrm{C}(5)-$

$\mathrm{C}(6)-\mathrm{O}(6)]$ is referred to as $\chi(5)$ and $\chi\left(5^{\prime}\right)$ in the unprimed and primed residues in Figure 1

* In all cases discussed here, the hydrogen atom positions given in the respective crystal structure reports were not used. Instead, these positions were computed such that the hydrogen attached to a carbon atom would be in the tetrahedral position, on the average, with respect to all the rest of the bonds attached to that carbon atom. A bond length of $\mathrm{C}-\mathbf{H}=1 \cdot 1 \AA$ was used. 
structures involving only glucose residues. None of the crystalline conformations of the free sugars involves $\mathrm{O}(6)$ or $\mathrm{O}\left(6^{\prime}\right)$ in an intramolecular hydrogen bond (either within its own residue or with an atom of the contiguous residue. Instead, they take part in intermolecular hydrogen bonds, with another sugar molecule or with water. There does not seem to be a regular pattern for the orientation of the $\mathrm{O}(6)$ or $\mathrm{O}\left(6^{\prime}\right)$ group.

In the case of acetyl cellobiose, the $\mathrm{O}(6)$ group of the unprimed residue is situated at $\chi(5)=-60^{\circ}$, whereas in cellobiose both $O(6)$ and $O\left(6^{\prime}\right)$ are in the same conformational relation to the ring, viz. $\chi(5)=\chi\left(5^{\prime}\right)=60^{\circ}$. If $\mathrm{O}(6)$ is disposed otherwise in acetyl cellobiose while keeping $\phi$ and $\psi$ the same as in cellobiose, then unacceptable short intramolecular contacts follow (cf. below).

\section{Valence angle at the bridge oxygen}

Considerable uncertainty exists in the literature as to the proper value for bond angle CÔC, at the bridge oxygen atom, for theoretical studies. Values ranging from $116^{\circ}$ to $119^{\circ}$ have been used by various' authors for different polysaccharides. Information available from the crystal structures reported so far shows a definite trend in the value of CÔC as given in Table 2, which

Table 2. Bridge oxygen angle, CÔC, in a selection of carbohydrate crystal structures

\begin{tabular}{ccc}
\hline Value of & CốC, \\
Molecule & Schematic of the situation
\end{tabular}

Methyl $\beta$-D-xyloside Methyl $\alpha$-D-glucoside Methyl $\alpha$-D-galactoside Methyl $\beta$-maltopyranoside Methyl $\beta$-cellobioside

Cellobiose 116.7

$\left.\begin{array}{l}113.4 \\ 113.0 \\ 113.3 \\ 113.2 \\ 113.1\end{array}\right\}$

Acetyl cellobiose Acetyl xylobiose

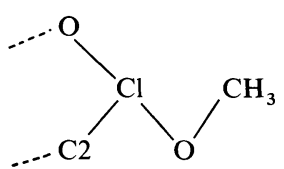

20

21

12

22

was constructed from data on selected structures. It is seen that while in methyl $\beta$-xyloside and other glycoside compounds the angle CÔC is only $113.0-113.4^{\circ}$, it increases to $116.7^{\circ}$ in the disaccharide cellobiose. Still larger 
values of $117.98^{\circ}$ and $117.9^{\circ}$ are found in acetyl cellobiose and acetyl xylobiose. This seems to indicate that the angle CÔC depends on the size of the 'substituent' at the C(1) atom-increasing as the aglycon moiety goes from a methyl group, to pyranose ring, to acetyl pyranose ring. This trend will be further tested as other studies on the crystal structures of various derivatives become available*.

The importance of the value used for CÔC in relation to theoretical conformational calculations related to cellulose was shown in a previous paper $^{24}$.

\section{CONFORMATIONAL MAPS}

One may compute the potential energy associated with a given conformation of a disaccharide as a sum of non-bonded, electrostatic and hydrogen bond energies between atoms of contiguous residues taken pairwise. The results are presented in terms of Ramachandran maps, as isoenergy contours in the $(\phi, \psi)$ space. A large number of such maps have been published using the geometry for the monomer residues as derived from the average of various crystal structure findings on mono- and disaccharides. Maps for derivatives such as acetyl disaccharides have not been reported so far, because the problem of accounting for the variation in preferred orientation of the substituents appeared formidable. However, examination of models shows that this is not a serious problem, since the freedom of rotation for the acetate groups about the respective $\mathrm{C}-\mathrm{O}$ bonds is very limited ${ }^{8}$.

With a view to examining the differences in the conformational features brought on by acetyl substitution, energy maps were computed for cellobiose, acetyl cellobiose and acetyl xylobiose. Contrary to previous practice, we used the exact crystal structure data for the respective disaccharides, but variation in the orientation of the $\mathrm{O}(6)$ group in cellobiose and acetyl cellobiose was allowed.

\section{Parameters for energy cakculations}

Threefold intrinsic torsional potentials with a barrier of $0.8 \mathrm{kcal} . \mathrm{mol}^{-1}$ were assigned to rotations $\phi$ and $\psi$ around the glycosidic bonds $\mathrm{C}(1)-\mathrm{O}$ and $\mathrm{O}-\mathrm{C}\left(4^{\prime}\right)^{25}$. Non-bonded interactions were computed using the Lennard-Jones 6-12 function. The parameters adopted for different atoms or groups are listed in Table 3. The methyl groups were treated as spherical domains of fixed size. Coulombic interactions were assessed by assigning partial charges ${ }^{26}$ to the atoms using bond moments ${ }^{27}$ (Debyes) of

$\begin{array}{llll}\mathrm{C}-\mathrm{C} & 0.0 & \mathrm{C}=\mathrm{O} & 0.39 \\ \mathrm{C}-\mathrm{O} & 0.82 & \mathrm{C}=\mathrm{O} & 0.74 \\ \mathrm{C}-\mathrm{H} & 0.38 & & \end{array}$

A value of 2.0 was used for the effective dielectric constant ${ }^{28}$. Hydrogen bond energies, where applicable, were estimated by an empirical ${ }^{9}$ inverse-thirdpower expression $\left(V=-55 / r^{3}\right)$.

* For studies on polymers involving linear carbon chains, a value of $110^{\circ}-114^{\circ}$ is used for the angle $\mathrm{C}^{\alpha} \mathrm{CC}^{\alpha}$ at the methylene carbon atom, e.g. for polypropylene; however, the need for a larger value, about $122^{\circ}$, for this angle in the case of polyisobutylene was realized when the crystal structure $^{23}$ of the model compound 2,2,4,4-tetramethyl adipic acid became available. 
Table 3. Parameters used for evaluating the non-bonded interaction energy

\begin{tabular}{lccc}
\hline Atom or group & $\begin{array}{c}\text { van der Waals } \\
\text { radius, } \AA\end{array}$ & $\begin{array}{c}\text { Effective } \\
\text { number of } \\
\text { electrons }\end{array}$ & $\begin{array}{c}\text { Polarizability, } \\
\mathbf{A}^{\mathbf{3}}\end{array}$ \\
\hline $\mathrm{C}$ & 1.7 & 5.0 & 0.93 \\
$\mathrm{C}$ (carbonyl) & 1.7 & 5.0 & 1.23 \\
$\mathrm{O}$ & 1.5 & 7.0 & 0.59 \\
$\mathrm{O}$ (carbonyl) & 1.5 & 7.0 & 0.84 \\
$\mathrm{H}$ & 1.2 & 0.9 & 0.42 \\
$\left(\mathrm{CH}_{3}\right)$ & 1.9 & 8.0 & 2.19 \\
\hline
\end{tabular}

\section{Cellobiose}

The energy maps calculated at intervals of $10^{\circ}$ in $\phi$ and $\psi$ for cellobiose with $\left[\chi(5), \chi\left(5^{\prime}\right)\right]=\left(60^{\circ}, 60^{\circ}\right)$ and $\left(-60^{\circ}, 60^{\circ}\right)$ are given in Figures $5(\mathrm{a})$ and $5(\mathrm{~b})$. The former is similar to the $\mathrm{O}(6)$ and $\mathrm{O}\left(6^{\prime}\right)$ orientation in the cellobiose crystal structure, while $\left[\chi(5), \chi\left(5^{\prime}\right)\right]=\left(-60^{\circ}, 60^{\circ}\right)$ resembles the situation in acetyl cellobiose, the aim being to examine the differences in the cellobiose isoenergy maps by keeping $\mathrm{O}(6)$ in the $+60^{\circ}$ and $-60^{\circ}$ positions (cf. Figure 4). All the possible intramolecular hydrogen bonds between atoms of contiguous residues are included in estimating the energies in this theoretical exercise.

Irrespective of the difference in the orientation of the $O(6)$ group, the minimum energy in the $(\phi, \psi)$ surface occurs at the same position, viz. $(\phi, \psi)=\left(40^{\circ},-20^{\circ}\right)$ in both maps; this point is within $5^{\circ}$ in $\phi$ and $\psi$ of the crystalline cellobiose conformation (denoted by CB). The striking difference, however, is the larger freedom of rotation (shallower energy minimum) afforded in Figure 5(b).

In Figure 5(a) overlaps between $\mathrm{O}(2)$ and members of the $\left(\mathrm{CH}_{2} \mathrm{OH}\right)^{\prime}$. group [cf. Figure 1(a)] are responsible for the high energy of the regions of negative $\phi$. For example, in the conformation $\phi=-20^{\circ}, \psi=-10^{\circ}$ the distances $\mathrm{O}(2) \ldots \mathrm{C}\left(6^{\prime}\right)$ and $\mathrm{O}(2) \ldots \mathrm{H}\left(6^{\prime}\right)$ are $2.45 \AA$ and $1.71 \AA$, respectively, and the severity of the overlap increases as the value of $\psi$ is increased. In the minimum energy state $\left(40^{\circ},-20^{\circ}\right)$ in Figure $5(\mathrm{a})$, the hydrogen bond distance $\mathrm{O}\left(3^{\prime}\right)-\mathrm{O}(5)$ is $2.7 \AA$. The distance increases as the value of $\psi$ is increased, with $3.12 \AA$ at $\left(40^{\circ}, 0^{\circ}\right)$. In the conformation $\left(40^{\circ},-20^{\circ}\right)$ there is also a weak intramolecular hydrogen bond between $O(6)$ and $O\left(3^{\prime}\right)$ hydroxyls (see i) (distance $3.16 \AA$ ), which becomes stronger as the value of $\psi$ is decreased, with $2.84 \AA$ at $\left(40,-40^{\circ}\right)$. However, the distance $\mathrm{O}\left(3^{\prime}\right)-\mathrm{O}(5)$ in this conformation is $2.4 \AA$, which is considerably lower than the normal hydrogen bond distance of 2.7-2.8 $\AA$ observed in carbohydrate crystal structures. Thus, the presence of $\mathrm{O}\left(3^{\prime}\right)-\mathrm{O}(5)$ and $\mathrm{O}(6)-\mathrm{O}\left(3^{\prime}\right)$ hydrogen bonds tends to stabilize the conformation $\left(40^{\circ},-20^{\circ}\right)$, with the energy increasing rapidly as one moves away from this conformation. The $\mathrm{O}(6) \ldots \mathrm{O}\left(3^{\prime}\right)$ distance is greater than the hydrogen bond limit for $\phi \leqslant 30^{\circ}$.

In Figure 5(b), where $\chi(5)=-60^{\circ}$, the $\mathrm{O}(6)---\mathrm{O}\left(3^{\prime}\right)$ hydrogen bonding possibility is precluded. Hence, the conformation $\left(40^{\circ},-20^{\circ}\right)$ is free of bias and the $1 \mathrm{kcal}$. $\mathrm{mol}^{-1}$ contour encompasses a larger area on the map.

The feature that the minimum energy conformation is the same in Figures 

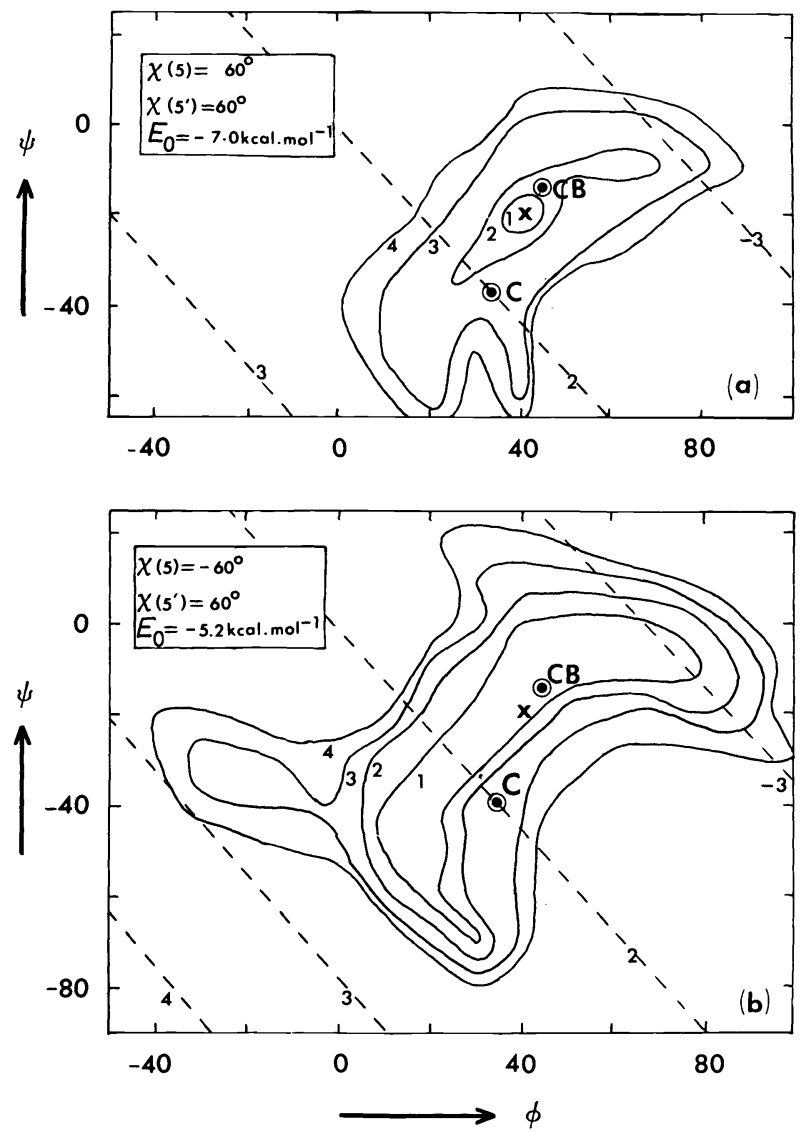

Figure 5. Energy diagram computed for cellobiose with (a) $\left[\chi(5), \chi\left(5^{\prime}\right)\right]=\left(60^{\circ}, 60^{\circ}\right)$ and (b) $\left[\chi(5), \chi\left(5^{\prime}\right)\right]=\left(-60^{\circ}, 60^{\circ}\right)$. Contours were drawn by interpolation of energies computed at intervals of $10^{\circ}$ in $\phi$ and $\psi$. The notations and definitions of $\phi$ and $\psi$ are given elsewhere ${ }^{30}$. Contours given at intervals of $1 \mathrm{kcal} . \mathrm{mol}^{-1}$ are expressed relative to the minima, marked by $X$, as zero energy in each case. The absolute energies, $E_{0}$, of the minima are given. $\odot$ CB denotes the crystalline conformation of cellobiose. $\odot \mathrm{C}$ : position of cellulose chain with $2_{1}$ screw along its axis. The curves of iso $n$ are given by dashed lines. Negative $n$ values denote left-handed helices

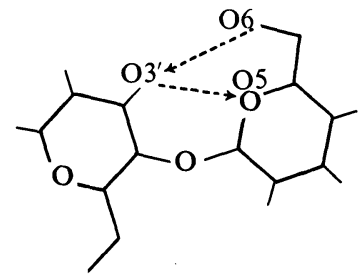

$5(\mathrm{a})$ and $5(\mathrm{~b})$ is significant. In one of them there is a weak $\mathrm{O}(6)---\mathrm{O}\left(3^{\prime}\right)$ hydrogen bond, which is not found in the crystal structure; in the actual crystal $\mathrm{O}(6)$ forms an intermolecular hydrogen bond. This shows that the 
presence of this hydrogen bond (intramolecular) in itself is inconsequential; only the $O\left(3^{\prime}\right)---O(5)$ hydrogen bond is important to predicting the preferred conformation, since its omission in the calculations causes a significant shift of the minimum energy away from CB. Secondly, this indicates that the intramolecular minimum energy conformation is most likely to correspond to the crystal structure and that disregard for intermolecular effects in the theoretical calculations, in itself, is not serious. This is in accordance with the conclusion of Jeffrey ${ }^{29}$ on the secondary importance of intermolecular hydrogen bonds in carbohydrate crystal structures in their influence on conformation.

Isoconformation contours of the helical parameter $n$ (which represents the number of residues per turn of the helix $)^{30,31}$ are given by dashed lines in Figure 5. These were calculated using the average geometry of the two residues in the cellobiose crystal structure. The position of cellulose with a twofold screw axis along the chain is marked by C. It is seen that this position is outside the contour for $2 \mathrm{kcal}^{-\mathrm{mol}^{-1}}$ in both Figures 5(a) and 5(b). In this conformation, $(\phi, \psi)=\left(35^{\circ},-40^{\circ}\right)$, the distance $\mathrm{O}(5) \ldots \mathrm{O}\left(3^{\prime}\right)$ is $2.4 \AA$, which is considerably shorter than observed hydrogen bond distances in carbohydrate structures*. In the absence of compelling evidence for such a short hydrogen bond distance, it is questionable indeed whether cellulose should be attributed a twofold screw axis along the chain, as has been frequently done in the past. Preliminary results on the crystal structure of cellotetraose indicates absence of a twofold screw axis along the oligomer ${ }^{32}$.

\section{Acetyl cellobiose}

The energy maps calculated for acetyl cellobiose are given in Figure 6(a) and $6(\mathrm{~b})$. In the former $\chi(5)=-60^{\circ}$, similar to that in the crystal structure and $\chi(5)=60^{\circ}$ in the latter. The $\phi, \psi$ coordinates corresponding to the crystalline conformation of acetyl cellobiose are marked by Ac and the minimum energy position by $\mathrm{X}$. In Figure 6(a) the minimum energy position is close to the crystal structure conformation, removed only by $5^{\circ}$ in $\psi$. It is also clear from the asymmetry of the isoenergy regions that the freedom of rotation is comparatively higher around the $\mathrm{C}(1)-\mathrm{O}$ bond (wider range of $\phi$ ) than around the $\mathrm{O}-\mathrm{C}\left(4^{\prime}\right)$ bond (limited range of accessible $\psi$ ). For a given $\phi$ in the range $30^{\circ}$ to $80^{\circ}$, the energy increases very rapidly in the range $\psi \approx 0^{\circ}$ to $10^{\circ}$. For example, when $\phi=50^{\circ}$ and $\psi=10^{\circ}$, the distance $\mathrm{O}(6) \ldots \mathrm{M}\left(3^{\prime}\right)$ is $2.95 \AA$ and this decreases to $2.3 \AA$ for $\psi=0^{\circ}$. Through the range $\phi=40^{\circ}$ to $70^{\circ}$ and $\psi=0^{\circ}$ to $10^{\circ}$, the severity of the $\mathrm{O}(6) \ldots \mathrm{M}\left(3^{\prime}\right)$ close contact persists as above.

Comparing Figures 6(a) and 5(a), we notice that the area of the $(\phi, \psi)$ map, within, say, the $4.0 \mathrm{kcal} . \mathrm{mol}^{-1}$ contour, is smaller (note difference in $\phi, \psi$ scales between Figures 5 and 6 ) in the case of acetyl cellobiose. While negative values of $\psi$ are preferred for cellobiose, only positive values of $\psi$ are acceptable for acetyl cellobiose. This is principally due to the steric conflict between the $\mathrm{O}(5)$ atom and $\mathrm{O}(6)$ acetate group, and the members of the $\mathrm{O}\left(3^{\prime}\right)$ acetate group (see ii). For example, at $(\phi, \psi)=\left(40^{\circ},-20^{\circ}\right)$, the distances $\mathrm{O}(5) \ldots \mathrm{O}\left(3^{\prime}\right)$,

\footnotetext{
${ }^{*}$ Use of other sets of average geometries for the $\beta$-D-glucose residue for generating the cellulose chain could increase this distance to about $2.5 \AA$, which is still shorter than the intramolecular H-bond in cellobiose (crystal structure), viz. $2.7 \AA$.
} 

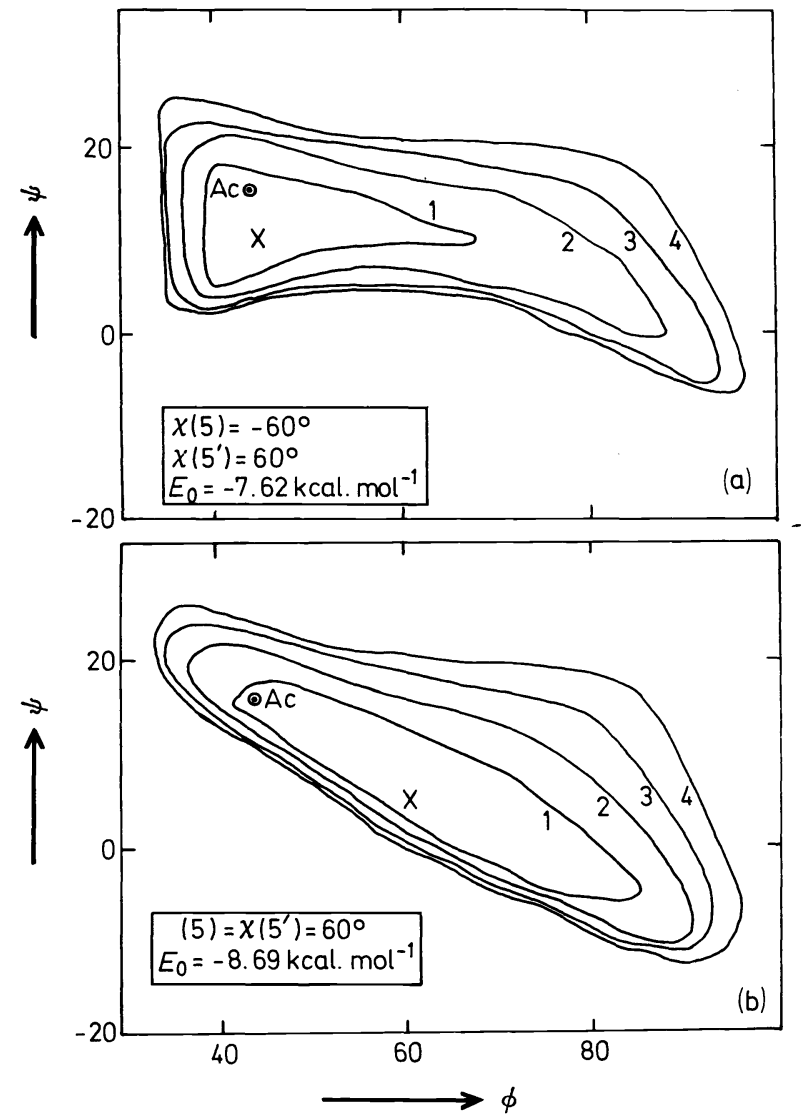

Figure 6. Energy contours computed for acetyl cellobiose at intervals of $5^{\circ}$ in $\phi$ and $\psi$. See legend for Figure 5. OAc: position of acetyl cellobiose crystal conformation

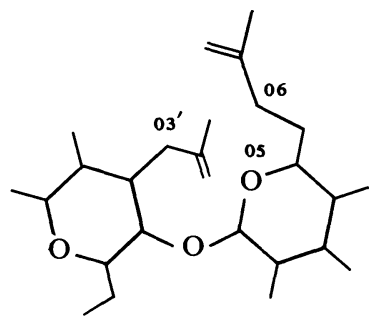

$\mathrm{O}(5) \ldots \mathrm{CA}\left(3^{\prime}\right), \mathrm{O}(5) \ldots \mathrm{OA}\left(3^{\prime}\right)$ and $\mathrm{O}(5) \ldots \mathrm{M}\left(3^{\prime}\right)$ are $2.6 \AA, 2.05 \AA, 2.3 \AA$ and $2.5 \AA$, respectively. In addition, close contacts are also found between $\mathrm{O}(6)$ and the $\mathrm{O}\left(3^{\prime}\right)$ acetyl groups: $\mathrm{O}(6) \ldots \mathrm{M}\left(3^{\prime}\right)=2.11 \AA, \mathrm{CA}(6) \ldots \mathrm{M}\left(3^{\prime}\right)=3.0 \AA$.

In Figure 6(b) the calculated minimum is far removed from the crystalline conformation. The conformation $\left(45^{\circ}, 10^{\circ}\right)$ [which represents the minimum in Figure 6(a)] is of high energy in Figure $6(\mathrm{~b})$ because, for $\chi(5)=60^{\circ}$, the 
conformation $\left(45^{\circ}, 10^{\circ}\right)$ entails close contacts between the $\mathrm{O}(6)$ acetate and the $\mathrm{O}\left(3^{\prime}\right)$ acetate $\left[\mathrm{CA}(6) \ldots \mathrm{M}\left(3^{\prime}\right)=3.1 \AA\right.$ and $\left.\mathrm{OA}(6) \ldots \mathrm{M}\left(3^{\prime}\right)=2.6 \AA\right]$. These are relieved by an increase of $\phi$; at $\phi=60^{\circ}, \psi=10^{\circ}$ there are no close contacts. The difference in the absolute energy of about $1 \mathrm{kcal}^{\mathrm{mol}}{ }^{-1}$ between Figures $6(\mathrm{a})$ and $6(\mathrm{~b})$ seems to be mainly because of the torsional energy contribution due to the rotation around the $\mathrm{C}(1)-\mathrm{O}$ and $\mathrm{O}-\mathrm{C}\left(4^{\prime}\right)$ bonds.

Thus, while in the case of cellobiose the presence of the $O\left(3^{\prime}\right)---O(5)$ hydrogen bond prevents any shift of the minimum for different orientations of the $\mathrm{O}(6)$ hydroxyl, in acetyl cellobiose the position of the minimum is dependent on the $\mathrm{O}(6)$ acetate group orientation. This is primarily due to the necessity of avoiding steric overlaps between the $\mathrm{O}(6)$ and $\mathrm{O}\left(3^{\prime}\right)$ acetate groups.

\section{Helical parameters}

The map of helical parameters $n$ and $h$ (the height of the residue projected on to the helix axis) computed in terms of $\phi$ and $\psi$, using the acetyl cellobiose geometry, is given in Figure 7. It is seen that the position of occurrence of crystalline acetyl cellobiose corresponds to $n \approx 3$. If acetyl cellobiose is considered to be similar to a segment of acetyl cellulose, then it would imply that the latter should be a helix with a threefold screw axis. The exact nature of the chain symmetry in acetyl cellulose is not established, although a detailed structure study has been made ${ }^{4}$.

Also given in Figure 7 are the helical parameters for cellulose calculated with the average geometry of the two residues as in the structure of cellobiose. Comparing these with the results obtained with acetyl cellobiose geometry, one notices significant differences. Though the angle CÔC is slightly different in the two cases, calculations show that the variation in $n$ and $h$ depicted in Figure 7 is mainly due to the differences in the residue geometry discussed above.
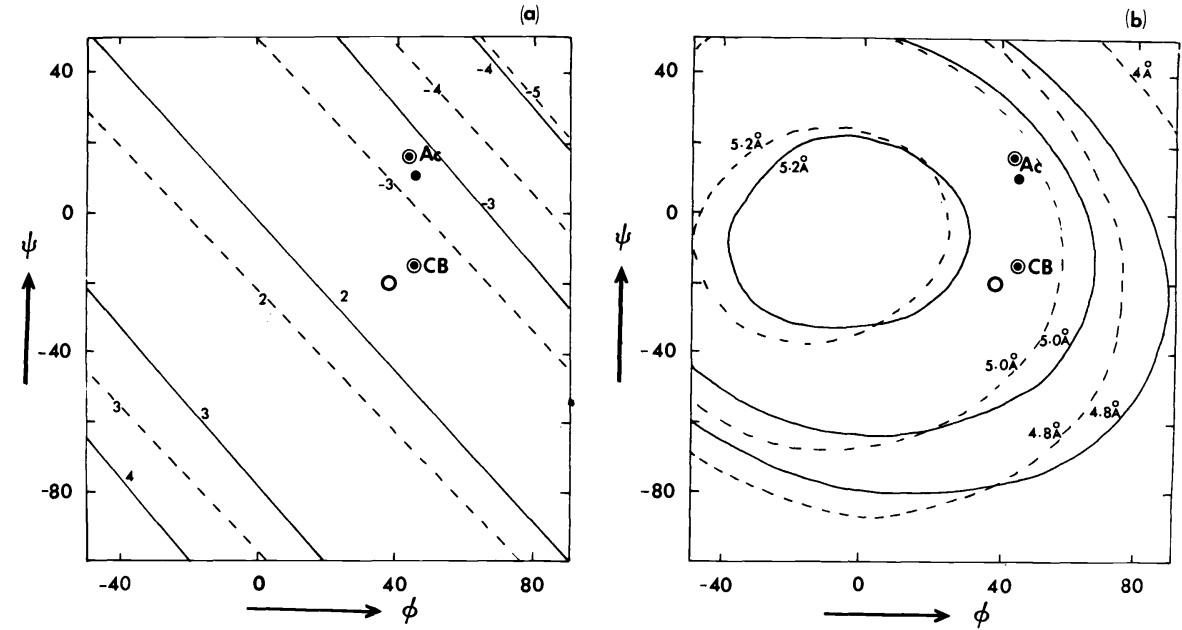

Figure 7. Curves of (a) iso $n$ and (b) iso $h$ computed at intervals of $10^{\circ}$ in $\phi$ and $\psi$ for cellobiose (solid curves; $\mathrm{COOC}=116.1^{\circ}$ ) and acetyl cellobiose (dashed curves; $\mathrm{CÔC}=118^{\circ}$ ). The respective crystal geometry is used in each case. The variation in the angle $C O$ OC itself does not contribute to the differences seen here. $\mathrm{OAc}=$ acetyl cellobiose $\mathrm{OCB}=$ cellobiose; $O=$ calculated energy minimum for acetyl cellobiose; $\bigcirc=$ calculated energy minimum for cellobiose 


\section{R. H. MARCHESSAULT AND P. R. SUNDARARAJAN}

In the past many workers have computed maps of helical parameters using various types of average geometry for the residues and have compared the crystalline conformations of disaccharides with polymer structures whose $(\phi, \psi)$ conformation was read off from the common $n, h$ map. The discrepancies noted in Figure 7 indicate that such comparisons should be viewed with some reservation, as they are approximate and sometimes misleading. It would seem that data for theoretical calculations on polymer structures should be derived from identical small molecules. Conformational discussions about substituted polysaccharides on the basis of calculations performed with data for unsubstituted oligomers will be approximate at best.

\section{Acetyl xylobiose}

The energy map for acetyl xylobiose in terms of $\phi$ and $\psi$ is given in Figure 8.

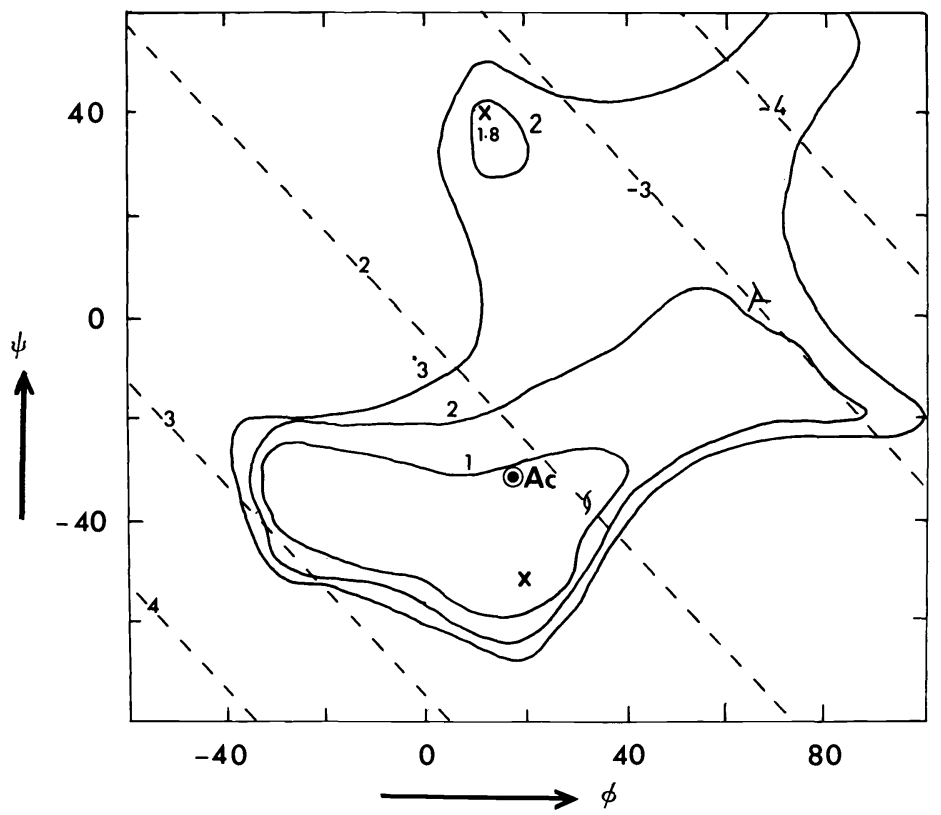

Figure 8. Energy diagram computed for acetyl xylobiose in terms of $\phi$ and $\psi$. See legend for Figure 5. $\mathrm{OAc}=$ crystal conformation of acetyl xylobiose. $\mathrm{X}=$ position of minimum energy $6=$ position of acetyl xylan with $2_{1}$ screw axis and repeat of $10.4 \AA, \lambda=$ hypothetical acetyl xylan chain with $3_{1}$ screw axis and a repeat of $14.85 \AA$. Dashed curves represent iso $n$ contours.

Negative $n$ values denote left-handed helices

It is readily apparent that the absence of the $C(6)$ atom (and the group attached to it) increases the freedom of rotation of the residues about the glycosidic bonds. The calculated minimum is removed from the crystalline conformation (Ac) by about $15^{\circ}$ in $\psi$, with a difference in energy of about $0.6 \mathrm{kcal}^{\mathrm{mol}} \mathrm{mol}^{-1}$. This difference in energy could easily be accounted for by the torsional energy itself. The curves of iso $n$ (calculated with acetyl xylobiose geometry) are also given by dashed lines. 
It is known that while xylan occurs with a threefold screw axis ${ }^{7}$ and a repeat of $14.85 \AA$, acetyl xylan is found to have a twofold screw axis ${ }^{8}$, with a repeat of $10.3 \AA$. It is seen from Figure 8 that the position of acetyl xylan occurs close to the calculated minimum energy position and the crystalline conformation of the disaccharide. Positions along the threefold screw axis, on the other hand, are of higher energy. This does not seem to be due to non-bonded interactions. In both conformations, $(\phi, \psi)=\left(30^{\circ},-35^{\circ}\right)$ (which corresponds to a 2, screw axis and a repeat of $10.3 \AA$ ) and $\left(70^{\circ}, 0^{\circ}\right)$ (which gives a. $3_{1}$ screw axis and a repeat of $14.85 \AA$ ), there are no close contacts. The difference in energy seems to arise due to the electrostatic attraction in the conformation $\left(30^{\circ},-35^{\circ}\right)$ between the $\mathrm{O}(5)$ atom and the $\mathrm{CA}\left(3^{\prime}\right)$ atom. Previous calculations ${ }^{8}$ on this aspect, using the 'average geometry' for the residues, showed both twofold and threefold helical chains of acetyl xylan to be of the same energy. The discrepancy seems to be mainly due to the neglect of electrostatic interactions in the previous work. In any event, it is of interest to note that the chain conformation of acetyl xylan is found to be close to the calculated minimum energy state in Figure 8. It may be recalled that theoretical calculations on xylan supported the $\mathrm{x}$-ray studies in proposing a threefold screw axis for the unsubstituted polymer ${ }^{23}$.

\section{Acetyl mannobiose}

The energy maps computed at intervals of $5^{\circ}$ in $\phi$ and $\psi$ for acetyl mannobiose with $\left[\chi(5), \chi\left(5^{\prime}\right)\right]=\left(-60^{\circ}, 60^{\circ}\right)$ and $\left(60^{\circ}, 60^{\circ}\right)$ are given in Figures $9(\mathrm{a})$ and $9(\mathrm{~b})$, respectively. The former is similar to the conformation of $\mathrm{O}(6)$ and $O\left(6^{\prime}\right)$ acetates in the crystalline structure of acetyl cellobiose. These maps were calculated with the coordinates for atoms in acetyl mannobiose, as derived from those of acetyl cellobiose, the $O(2)$ and $O\left(2^{\prime}\right)$ groups having been duly transferred axial.

Comparing Figures 6(a) and 9(a), we notice that the range of acceptable $\psi$ remains the same, whereas the range of $\phi$ within the contour for $4.0 \mathrm{kcal}^{\mathrm{mol}}{ }^{-1}$ is higher in the case of acetyl mannobiose. The calculated minimum in Figure 9(a) occurs at $\left(65^{\circ}, 10^{\circ}\right)$ instead of at $\left(45^{\circ}, 10^{\circ}\right)$, as found in Figure $6(\mathrm{a})$ for acetyl cellobiose.

Figure 9(b) shows that the range of accessible $\phi$ and $\psi$ is very limited when $\chi(5)=60^{\circ}$ [compare Figure 9(a) and also Figure 6(b)] in acetyl mannobiose. The minimum occurs at $\left(35^{\circ}, 20^{\circ}\right)$, which is close to the crystal conformation of acetyl cellobiose. The conformation $\left(65^{\circ}, 10^{\circ}\right)$, which was of minimum energy in Figure 9(a), happens to be of high energy in Figure 9(b). With $\chi(5)=60^{\circ}$, severe steric overlaps result for $(\phi, \psi)=\left(65^{\circ}, 10^{\circ}\right)$, as follows: $\mathrm{CA}(6) \ldots \mathrm{M}\left(2^{\prime}\right)=3.0 \AA, \mathrm{M}(6) \ldots \mathrm{CA}\left(2^{\prime}\right)=3.4 \AA$ and $\mathrm{M}(6) \ldots \mathrm{M}\left(2^{\prime}\right)=2.0 \AA$.

Locating the above minimum energy conformations in the helical parameter plot of Figure 7, we find that $(\phi, \psi)=\left(65^{\circ}, 10^{\circ}\right)$ [minimum in Figure 9 (a)] gives $n \approx 3.6$ and $h \approx 4.8 \AA$; on the other hand, $(\phi, \psi)=\left(35^{\circ}, 20^{\circ}\right)$ [minimum in Figure 9(b)] gives $n \approx 3.0$ and $h \approx 5.1 \AA$. The latter is identical with the $\mathrm{x}$-ray observation ${ }^{6}$ that acetyl mannan occurs with a threefold screw axis and a repeat of $15.24 \AA$. Hence, it would seem from these calculations that in acetyl mannan $\chi(5)=60^{\circ}$ would be preferred for the $O(6)$ acetate groups and the chain conformation would be similar in $(\phi, \psi)$ to the acetyl cellobiose molecule. 
R. H. MARCHESSAULT AND P. R. SUNDARARAJAN

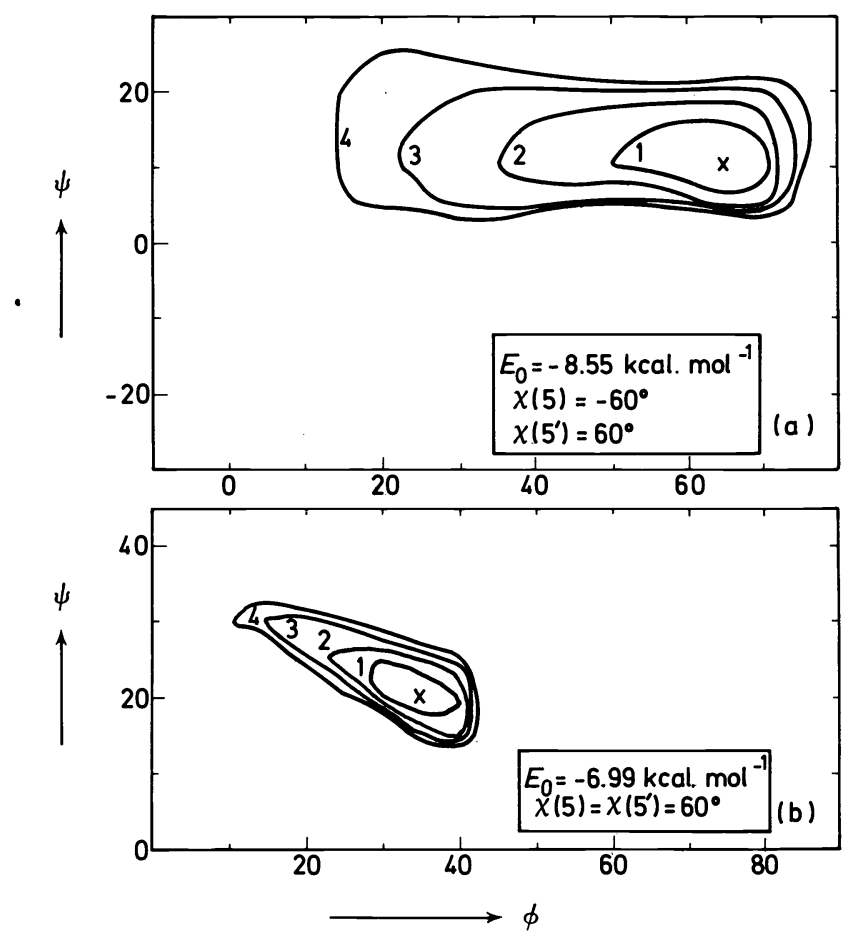

Figure 9. Energy diagrams computed for acetyl mannobiose in terms of $\phi$ and $\psi$. See legend for Figure 5

\section{CONCLUSION}

The data and calculations presented here show that the effect of acetate substitution is significant for disaccharides containing hexapyranose residues and not so appreciable for pentapyranose disaccharide. The information available in either case, however, is limited. In both types of polymers, the chain conformation is affected, which seems to be due, primarily, to the intramolecular forces. Our knowledge at this time on this aspect is still in its embryonic state. In any case, caution should be exercised in the choice of residue geometries for theoretical analysis. Further crystal structure studies on free and acetyl di- and oligosaccharides would doubtless aid in our grasping the conformational features of substituted polysaccharides.

\section{ACKNOWLEDGEMENTS}

This work was supported by a grant from the National Research Council of Canada. The authors thank Dr F Leung for many helpful discussions. 


\section{REFERENCES}

${ }^{1}$ H. O. Bouveng, P. J. Garegg and B. Lindberg, Acta Chem. Scand. 14, 742 (1960).

2 H. Meier, Acta Chem. Scand. 15, 1381 (1961).

${ }^{3}$ K. H. Meyer and L. Misch, Helv. Chim. Acta, 20, 232 (1937);

H. J. Wellard, J. Polymer Sci. 13, 471 (1954).

4 W. J. Dulmage, J. Polymer Sci. 26, 277 (1957).

5 E. Frei and R. D. Preston, Nature (Lond.), 192, 939 (1961);

I. Nieduszynski and R. H. Marchessault, Canad. J. Chem. 50, 2130 (1972).

6 H. Bittiger and R. H. Marchessault, Carbohyd. Res. 18, 469 (1971).

7 R. H. Marchessault and C. Y. Liang, J. Polymer Sci. 59, 357 (1962);

R. H. Marchessault and W. J. Settineri, J. Polymer Sci. B2, 1047(1964).

8 S. M. Gabbay, P. R. Sundararajan and R. H. Marchessault, Biopolymers, 11, 79 (1972);

P. R. Sundararajan and R. H. Marchessault. Biopolymers, 11, 829 (1972).

9 J. Blackwell, A. Sarko and R. H. Marchessault, J. Mol. Biol. 42, 379 (1969).

10 A. Sarko and R. H. Marchessault, Science, 154, 3757 (1966);

A. Sarko and R. H. Marchessault, J. Amer. Chem. Soc. 89, 6454 (1967).

11 C. C. F. Blake, D. F. Koenig, G. A. Mair, A. C. T. North, D. C. Phillips and V. R. Sarma, Nature (Lond.), 206, 757 (1965);

D. C. Phillips, Scientific American, 215, 78 (1966).

12 S. S. C. Chu and G. A. Jeffrey, Acta Cryst. 23, 1038 (1967).

13 G. Quigley, A. Sarko and R. H. Marchessault, J. Amer. Chem. Soc. 92, 5834 (1970).

14 S. S. C. Chu and G. A. Jeffrey, Acta Cryst. B24, 830 (1968).

15 F. Leung, H. D. Chanzy and R. H. Marchessault, in preparation (1975).

16 F. Leung and R. H. Marchessault, Canad. J. Chem. 51, 1215 (1973).

17 See, for example, IUPAC-IUB Commission on Biochemical Nomenclature, Arch. Biochem. Biophys. 145, 405 (1971); J. Mol. Biol. 52, 1 (1970).

18 S. Arnott and W. E. Scott, J. Chem. Soc., Perkin II, 324 (1972).

19 C. J. Brown, G. Cox and F. J. Llewellyn, J. Chem. Soc. (A), 922 (1966).

20 H. M. Berman and S. H. Kim, Acta Cryst. B24, 897 (1968).

21 J. H. Robertson and B. Sheldrick, Acta Cryst. 19, 820 (1965).

22 J. T. Ham and D. G. Williams, Acta Cryst. B26, 1373 (1970).

23 E. Benedetti, C. Pedone and G. Allegra, Macromolecules, 3, 16 (1970).

${ }^{24}$ P. R. Sundararajan and R. H. Marchessault, Canad. J. Chem., 50, 792 (1972).

25 N. Yathindra and V. S. R. Rao, Biopolymers, 9, 783 (1970).

26 D. A. Brant, W. G. Miller and P. J. Flory, J. Mol. Biol. 23, 47 (1967).

27 C. P. Smyth, Dielectric Behaviour and Structure, p 244. McGraw-Hill: New York (1955).

28 G. N. Ramachandran, Int. J. Protein Res. 1, 5 (1969).

29 G. A. Jeffrey, in R. F. Gould (Ed.), Carbohydrates in Solution, p 177. Advances in Chemistry Series 117, American Chemical Society (1973).

30 P. R. Sundararajan and V. S. R. Rao, Biopolymers, 8, 313 (1969).

31 C. Ramakrishnan, Proc. Indian Acad. Sci. A59, 327 (1964).

32 J. Poppleton and A. McL. Mathieson, Nature (Lond.), 219, 1046 (1968).

33 P. R. Sundararajan and V. S. R. Rao, Biopolymers, 8, 305 (1969). 